\title{
HUMOS NEGROS EN ADVIENTO METROPOLITANO
}

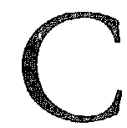

REO QUE FUE EN EL VERANO de I975 cuando recibí la invitación de la Universidad Autónoma Metropofesor invitado a intercambiar experiencias pedagogicas y dictar fesor invitado a intercambiar experiencias pedagógicas y dictar algunas clases en los espacios universitarios que se iban construyendo en esta unidad en el norte metropolitano de la Ciudad de México.

Como bien señala el profesor Antonio Toca en su reciente trabajo, Baubaus: mito y realidad', en México la estructura tradicional de las universidades y el desconocimiento de la actividad del diseño motivaron que no se planteara la necesidad de una carrera especializada hasta la aparición en I 969 de la primera licenciatura en diseño gráfico e industrial en la Universidad Iberoamericana, concibiéndose en I974 la fundación de la UAM con una nueva estructura académica que superara la tradicional organización de escuelas o facultades por divisiones en áreas de conocimiento, que abarcaban desde las ciencias biológicas y de la salud hasta las artes para el diseño.

Espacios y tiempos de nuevos modelos universitarios acontecieron por aquellos días como iluminaciones de adviento, fiesta abierta a la utopía de fundar ciudad, en una metrópoli como el D. F. gaseada de manera inmisericorde por tanto humo negro que impregnaba los rostros en la dura corteza

7 Antonio Toca Fernández, Ciudad de México: Universidad Autónoma Metropolitana, 2014. 
del habitar urbano; pero la ciudad siempre promete, y «si el aire es el secreto de otra luz, / podríamos salvarnos»".

Vivíamos en España las tensiones de unos años de olvidos necesarios y de mediocridad institucionalizada, como habitantes de un planeta ya transformado; con sus esperanzas democráticas, con sus mitos incipientes, sus dramas digitalizados y los hechizos que anunciaban las tribus cibernéticas en busca de ilusiones dormidas o prerrogativas sedimentadas en nuestras propias biografías, memoria y deseo quedaban acodalados en la lectura transversal de aquella ilustrada aventura mexicana.

«La intención era, y es -nos recuerda A. Toca- que la enseñanza se relacione con las investigaciones en cada campo de conocimiento, para hacer que el profesor y los alumnos, compartan información actualizada en su campo de trabajo»?.

Un grupo de jóvenes profesores-investigadores ${ }^{10}$ profesaban en aquellos seminarios donde impartir las nuevas formas de pensamiento en el diseño, en todo su proceso y estructura creativa, tarea pedagógica dura y contradictoria al tener que controlar y acotar el enigma funcionalista del siglo XX, las conquistas de la vanguardia plástica, junto a las monumentales arquitecturas de formas que glosaban con idílica información las «artes del relieve», por principio algo desnaturalizado del edificar constructivo de la arquitectura; de manera que aquel postulado de un expresionismo protector para el proyecto de la arquitectura, junto al axioma de la función, paradigma de tantos credos imposibles, se levantaban como hostiles murallas para poder liberar la provincia sitiada del Diseño ${ }^{11}$.

: José Ángel Valente, El fulgor. Antología poética (1953-1996), Barcelona: Galaxia Gutenberg-Círculo de Lectores, 1998 , p. 60.

- Antonio Toca Fernández, op. cit.

to Los trabajos de grupos interdisciplinares estaban dirigidos por el arquitecto Martín L. Gutiérrez; por lo que respecta a la coordinación de las relaciones entre arquitectura, diseño, comunicación y diseño industrial, por el arquitecto Jorge Sánchez Antuñano, junto a jóvenes arquitectos como Antonio Toca, María Teresa Ocejo, o Manuel Sánchez de Carmona, profesores con los que sellamos una enriquecedora amistad; más tarde pude contribuir a enriquecer la lista de profesores invitados, como el profesor Roberto Fernández, los diseñadores Gui Bonsiepe, Tves Zimmermann y el filósofo Eduardo Subirats.

- No era de extrañar que los efectos de la colonización simbólica de una arquitectura automática sin apenas referencia crítica que lleva a cabo la cultura 
Los debates académicos que reformulaban en las nuevas áreas de conocimiento en la UAM trataban de clarificar la ingente información que afloraba de los campus de la otra Américafrontera, para poder precisar con objetividad científica el dudoso discurso del parecer al ser de nuestro inmediato presente, captar la filosofía que encerraba el pensamiento teórico-práctico del acto de diseñar en su vasta y necesaria diferenciación funcional sin olvidar que «lo nuevo radical, como aseveraba Eliot, procede de lo antiguo intemporals.

Sin olvidar, por supuesto, una parte considerable del pensamiento crítico orientado a la reflexión teórica del diseño de objetos tan elocuente en los escritos de Tomás Maldonado (I970) a las cuestiones del método de proyectar, el universo de los objetos, la mimesis artística, o de la revisión del papel social de las universidades, apuntes que esbozaban por aquellos años en Azcapotzalco los preludios de un proyecto planificatorio ambiental.

Las escuelas de Arquitectura mexicanas y europeas mostraban cómo los espacios de la ciudad moderna, década de los setenta (siglo $\mathrm{XX}$ ), ya catalogaban suficientes manifiestos para honrar su memoria en las crónicas de la historia contemporánea de la arquitectura. No obstante, como fieles epígonos, intentábamos disfrutar también en el campus mexicano de la UAM de la «polifonía de formas», recibidas como realidades que lograran cumplir, con precisión tardía, las olvidadas promesas del Siglo de las Luces y en los claros del bosque tecnológico: más luz, más verde, más libertad; inmolábamos, sin saber que ya éramos epígonos desencantados, honores irónicos hacia aquellos paralelepípedos de agónica geometría.

No faltaban en aquella poliédrica década de los setenta canónicas tendencias arquitectónicas que se acantonaban en las aulas de las escuelas of facultades donde se dibujaba e ilustraba su razón crepuscular. Sus dioses desaparecían como efigies sin apenas recibir la temprana luz de la aurora; «agonías discretas» del viejo monasterio y de los solitarios publicistas se incorporaban

de imágencs en los que se educa al arquitecto no aceptara de buen grado los postulados básicos del trabajo del diseñador, ligado a una formación teóricopráctica más reflexiva frente al objeto. 
de nuevo bajo los epígrafes de diseñadores de culto a esgrafiar el proyecto de la arquitectura de la ciudad sobre oníricos dibujos, después de la refriega de estilos que significó el abandono de la tipología y el estereotipo. La publicidad se formalizaba como elemento compositivo del edificio, la función se iba transformando en mensaje porque en la colonización de los espacios de la ciudad, de alguna manera, el edificio era ya puro diseño del significado, así resultaba evidente en la calle metropolitana, desde las latas de Warhol a las contradicciones de R. Venturi. Arquitectos $\mathrm{y}$ disefiadores se apresuraban por interrogar a la forma y difuminar el espacio del edificio, para tener algo que admirar entre creadores, epígonos y militantes.

La nueva estructura académica de las tres áreas metropolitanas de la UAM se enfrentaban a una obstinada mentalidad gremial e ideológica de las costumbres vigentes y al debate visual que arropaba el proyecto de la arquitectura para la nueva metrópoli, que seguía atrincherado en su planeamiento por una política de la imagen como espectáculo y una vida pública ficticia, donde el consumo era el fundamento del prestigio y rango social. El edificio co mo objeto arquitectónico autónomo se entregaba con delirio a una envolvente en sus fachadas de transparencias ilusorias, que depositaban las maclas cristalinas liberadas de pertenencia alguna a la lógica de la ciudad.

El arquitecto, un tanto turbado, se iba convirtiendo en un esteta calígrafo y sus proyectos y enseñanzas, también como los artistas, pretendían liberarse de su mala conciencia con el trabajo bien hecho, residuos al fin de una poética cuyos primeros trabajos ya estaban consagrados en Nuevas Academias.

Enseñar en aquellos tiempos resultaba como siempre, también aquí en el incipiente campus de la UAM-A, abrazar el enigma de la incertidumbre y estar convencido de que «tanto nuestras verdades como nuestros proyectos, espacios y formas en la construcción de la ciudad, no son superiores a los de nuestros antepasados»; junto a ello se percibía en la dialéctica de profesores y alumnos una decidida voluntad didáctica de abandonar la «magia tecnológica» por un pensamiento científico-artístico, para poder formalizar el espacio de la arquitectura desde la sensatez racional de las necesidades humanas.

Pese a todo ello, entusiasmo fundador y sensatez racional no faltó en los nuevos horizontes que propiciaban la autonomía 
universitaria metropolitana en la gran ciudad mexicana, los avatares simbolistas ya presentes en aquellos años aparecían como una alternativa a los agotados presupuestos abstractos que aún soportaba el racionalismo escolástico: el arte como un juego de reflejos, la arquitectura como un instrumento que acoge bajo su construcción los objetos materiales, el principio de la economía como producción de deseos y reproducción de objetos complementarios al deseo y el objeto material como iluminada metamercancía, como no buscar en el diseño una corrección racional a derivadas tan señaladas.

El retorno y encuentro con la primaria y esencial voluntad didáctica, creo confirmar, que no estuvo ausente en el alma mater de la UAM-A, para desarrollar la búsqueda en la indagación de la tecnociencia moderna y la creación artística, que desde el conocimiento, en este caso de los postulados del diseño, permitiera edificar y superar el encanto utópico de la ciudad clásica, humanista e ilustrada, que hacían elocuente, desde su morfología metropolitana, que la vida sin la belleza sería un error.

De aquellos años aprendí a vislumbrar como tesis de esperanza, que «los malos días pasarán» para la construcción de la nueva metrópoli, más allá de la vieja ciudad y de los totalitarismos modernos de la cultura mediática, mercantil y espectacular, y que su síntesis ha de nacer de una precisa y decidida voluntad didáctica, ética y crítica, que integre en sus conocimientos los postulados filosóficos, científicos y artísticos contemporáneos para la construcción de la realidad habitable del siglo XXI. 